\title{
Implementasi E-learning Berbasis Assessment For Learning Untuk Meningkatkan Performa Belajar Mahasiswa
}

\author{
Ryan Ardiansyah, dan Dea Diella \\ Pendidikan Biologi, Fakultas Keguruan dan Ilmu Pendidikan, Universitas Siliwangi \\ Jl. Siliwangi No. 24, Tasikmalaya 46115, Indonesia. \\ e-mail: ryanardiansyah@unsil.ac.id
}

\begin{abstract}
Abstrak
Penelitian ini bertujuan untuk mengungkap pengaruh implemenetasi E-learning berbasis Assessment for learning terhadap performa belajar mahasiswa. Performa belajar mahasiswa terdiri atas hasil belajar, motivasi belajar dan aktifitas (keaktifan) belajar yang meliputi aktifitas bertanya dan memberikan tanggapan dalam proses diskusi di kelas. Metode yang digunakan untuk mencapai tujuan penelitian adalah metode true eksperimen. Desain yang akan digunakan yaitu posttest only control group - design. Kelompok eksperimen dan kontrol akan mendapatkan posttest. Partisipan penelitian ini adalah perwakilan mahasiswa semester 4 yang mengontrak matakuliah evaluasi dan asesmen. Instrumen penelitian yang digunakan meliputi soal kognitif untuk menjaring data hasil belajar, angket motivasi untuk menjaring data motivasi, dan lembar observasi keaktifan. Temuan penelitian ini menunjukkan bahwa elearning berbasis assessmen for learning $(A f L)$ berupa pemberian feedback menunjukkan pengaruh yang signifikan terhadap hasil belajar, motivasi dan keaktifan. Perlakuan terhadap hasil belajar memiliki effect size sebesar 0.60 yang berarti sedang.
\end{abstract}

\section{Kata Kunci-Assessment For Learning, E-learning, Feedback, Performa Belajar}

\begin{abstract}
This study aims to reveal the influence of implementation of E-learning based Assessment for learning on student learning performance. Student learning performance consists of learning result, learning motivation and learning activities which include asking questions and giving responses in the discussion process in class. The method used is true experiment. The design used is posttest only control group design. The experimental and control groups will get the posttest. The participants of this study were representatives of students in 4th semester who took evaluation and assessment courses. The research instruments used included cognitive questions to capture learning result data, motivation questionnaires to capture motivation data, and activeness observation sheets. The findings of this study show that E-learning based on Assessment for Learning $(A f L)$ with giving feedback show a significant influence on learning results, motivation and activity. The treatment of learning results has an effect size of 0.60 which mean in medium category
\end{abstract}

Keywords: Assessment for Leanring, E-learning, Feedback, Learning Performance

\section{PENDAHULUAN}

Proses pembelajaran harus senantiasa diperbaiki agar sejalan dengan perkembangan zaman yang menuntut efektivitas dan efisiensi dalam segala hal. Belajar menjadi proses yang dinamis karena tidak hanya terpusat di ruang kelas (Garrison \& Vaughan, 2017). Beragam teknologi media pendidikan dan komunikasi turut andil dalam memfasilitasi proses belajar di abad
Abad 21 ini. Teknologi sudah menjadi bagian dari kebutuhan hidup (Azizah, Khuzaemah, \& Rosdiana, 2017). Namun, teknologi pendidikan yang sudah ada belum dimanfaatkan secara maksimal oleh sebagian kalangan. Salah satu teknologi pendidikan yang digunakan sebagai media yaitu E-learning (Istambul, 2016). Media ini dapat memfasilitasi mahasiswa untuk zmemperoleh informasi terkait materi perkuliahan, tempat unggah tugas dan umpan balik (feedback), diskusi de- 
ngan sejawat maupun dosen, dan untuk pemberian kuis atau bentuk tes lainnya (Özad \& Kutoğlu, 2010).

Fasilitas teknologi pendidikan berupa E-learning telah disediakan oleh pihak universitas. Peneliti telah satu kali menggunakan fasilitas tersebut untuk media pengunggahan materi perkuliahan setiap pertemuan serta pengumpulan tugas mahasiswa. Mahasiswa memberikan respon positif terhadap penggunaan E-learning tersebut karena mempermudah mereka dalam mengakses informasi (kumpulan materi perkuliahan) dan paperless dalam pengumpulan tugas (Ghavifekr \& Rosdy, 2015). E-learning dapat diakses melalui komputer dan aplikasi moodle di telepon seluler (Ulva, Kantun, \& Widodo, 2018).

Peneliti bermaksud untuk meningkatkan pemanfaatan e-learning untuk proses asesmen. Asesmen dan proses belajar mengajar tidak dapat dipisahkan (Alruwais, Wills, \& Wald, 2018). Kualitas proses dan hasil belajar akan tercermin dari sejumlah informasi yang dikumpulkan melalui asesmen (Cox \& Godfrey, 1997). Efektifitas model pembelajaran, efisiensi media, kesulitan belajar mahasiswa, pemantauan ketercapaian tujuan pembelajaran dapat terungkap dari hasil asesmen. Mengacu pada hal tersebut bahkan asesmen menjadi bagian vital dari suatu proses pendidikan (HPSC, 2009).

Pelaksanaan asesmen sumatif masih menjadi fokus utama dan banyak dilaksanakan oleh pendidik dalam menentukan kualitas atau performa belajar (Boffey, 1970). Hal ini sangat disayangkan mengingat asesmen sumatif ini hanya berfokus pada tes di akhir kegiatan pembelajaran (Don, 2017). Idealnya selain asesmen sumatif, pendidik juga melaksanakan asesmen formatif atau nama lainnya Assessment for Learning (Ponte, Paek, Braun, Trapani, \& Powers, 2009). Asesmen formatif atau AfL ini akan mengungkap performa dan perkembangan belajar mahasiswa yang dapat dilihat dari setiap tugas yang telah dilaksanakan selama satu semester. Kunci utama dari pelaksanaan AfL ini adalah adanya timbal balik (feedback) dari pendidik untuk setiap tugas yang telah dilaksanakan oleh mahasiswa (AmuaSekyi, 2016). Pemberian feedback secara berkala diharapkan dapat membantu mahasiswa dalam meningkatkan hasil belajarnya dan memantau ketercapaian tujuan pembelajarannya (Ponte et al., 2009). Mahasiswa akan fokus dalam proses pembelajaran dan tidak hanya mengejar nilai akhir saja. Mahasiswa akan sadar bahwa proses juga penting karena selama proses belajar mereka akan menabung nilai yang terangkum dalam sejumlah tugas dan kinerja yang senantiasa dipantau dan dinilai oleh dosen. Proses inilah yang diharapkan menjadi bagian dari perkembangan performa belajar mahasiswa. Sejalan dengan teori konstruktivistik Vygotsky (!997) bahwa setiap pembelajar akan mendapatkan bantuan dari ahli (pendidik) untuk melalui Zone of Proximal Development (Shabani, Khatib, \& Ebadi, 2010).

Penelitian ini akan menggunakan e-learning sebagai media belajar sekaligus asesmen formatif bagi mahasiswa dalam perkuliahan evaluasi dan asesmen pembelajaran biologi. Semua aktifitas mahasiswa berupa akses materi perkuliahan, unggah tugas, pemberian feedback dari dosen, diskusi dan kuis akan dilaksanakan melalui e- learning.

Berdasarkan uraian latar belakang di atas maka dapat dirumuskan tiga permasalahan yakni,

a. Bagaimana pengaruh implementasi E-learning berbasis Assessment for Learning terhadap hasil belajar mahasiswa?

b. Bagaimana pengaruh implementasi E-learning berbasis Assessment for Learning terhadap motivasi belajar mahasiswa?

c. Bagaimana pengaruh implementasi E-learning berbasis Assessment for Learning terhadap aktifitas belajar mahasiswa?

\section{METODE PENELITIAN}

Penelitian ini akan menggunakan pembelajaran biologi. Motivasi belajar akan dijaring dengan menggunakan angket. Instrumen metode penelitian kuantitatif true experiment dengan desain posttest only control group - design. Kelompok eksperimen mendapat perlakuan dan kedua kelompok (eksperimen dan control) mendapatkan posttest (Creswell \& Garrett, 2014).

Kelompok eksperimen mendapat perlakuan berupa implementasi E- learning berbasis Assessment for Learning selama satu semester dalam mata kuliah evaluasi dan asesmen pembelajaran biologi di mana pemberian feedback dilakukan 
melalui e-learning secara kelompok dan individu sedangkan kelas kontrol feedback dilakukan di kelas secara konvensional. Penelitian ini dilakukan di Jurusan Pendidikan Biologi FKIP Universitas Siliwangi Kota Tasikmalaya. Partisipan penelitian terdiri atas dua kelas (satu kelas kontrol dan satu kelas eksperimen) yang merupakan mahasiswa semester 4 yang mengontrak mata kuliah tersebut dan dipilih sesuai dengan aturan randomisasi pada true experiment. Partisipan pada masing- masing kelas berjumlah 30 orang

Peubah yang akan diukur dalam penelitian ini adalah performa belajar mahasiswa yang diuraikan ke dalam tiga komponen sebagai berikut berserta dengan instrumennya :

a. Hasil belajar, merupakan hasil akhir ketercapaian tujuan pembelajaran. Hasil belajar diukur dengan tes akhir berupa soal uraian yang dirumuskan berdasarkan indikator capaian hasil belajar matakuliah evaluasi dan asesmen pembelajaran biologi (Kurniawan, 2017). Instrumen hasil belajar memiliki validitas sebesar 0.81 dan reliabilitasnya 0.89 .

b. Motivasi belajar, merupakan gambaran motivasi secara umum terhadap proses perkuliahan matakuliah evaluasi dan asesmen. Motivasi diberikan di minggu pertama perkuliahan. Instrumen yang digunakan merujuk pada Instruction Coures Interest Survey yang dikembangkan oleh Keller. Angket terdiri atas 34 pernyataan yang terdiri atas penyataan untuk komponen ARCS (Attention, Relevance, Confidence, Satisfaction) (Patonah, Rahardjo, Cari, \& Sajidan, 2017).

c. Aktifitas belajar, merupakan aktifitas yang ditunjukan selama mengikuti proses perkuliahan matakuliah evaluasi dan asesmen pembelajaran biologi yang terdiri atas aktifitas (1) bertanya dan (2) memberi tanggapan selama diskusi. Pertanyaan dan tanggapan dihitung jumlahnya dalam setiap pertemuan (total ada 10 topik diskusi) (Sanchez, 2011).

Pembuktian pengaruh perlakuan terhadap varibel terikat dihitung dengan menggunakan jenis uji $\mathrm{T}$ yakni independent t-test untuk data yang memenuhi pengujian prasyarat parametrik (berdistribusi norma dan homogen) dan uji Mann Whitney U untuk data yang tidak memenuhi uji prasyarat (tidak berdistribusi norma dan tidak homogen). Uji ini akan membuktikn pengaruh perlakuan terhadap variabel terikat melakui perbandingan dua rerata dari dua kelompok yang tidak berhubungan. Besarnya pengaruh perlakuan dihitung dengan rumus Cohen (Ozaki, 2008) .

\section{HASIL DAN PMBAHASAN}

\section{A. Hasil Belajar}

Salah satu performa belajar mahasiswa ditunjukkan dengan capaiannya dalam hasil belajar yang dijaring melalui teknik tes dengan instrument soal uraian. Data hasil belajar diambil melalui Ujian Tengah Semester (UTS) dan Ujian akhir Semester (UAS) kemudian dihitung rataratanya. Berdasarkan uji normalitas dengan Kolmogorov-Smirnov Test diperoleh Sig sebesar 0.200 untuk kelas eksperimen dan 0.200 untuk kelas kontrol. Kedua nilai Sig tersebut lebih besar dari 0.05 maka kedua data disimpulkan berdistribusi normal.

Uji hipotesis dilanjutkan dengan menggunakan uji $\mathrm{T}$ independent dan hasilnya dapat dilihat pada tabel 5.3. Hipotesis yang dirumuskan adalah sebagai berikut ,

H0 : tidak terdapat perbedaan antara rata-rata hasil belajar kelas eksperimen dengan kelas kontrol

Ha : terdapat perbedaan antara rata-rata hasil belajar kelas eksperimen dengan kelas kontrol

Dasar pengambilan keputusan

1. Jika nilai signifikansi atau Sig (2-tailed) > 0.05 , maka H0 diterima dan Ha ditolak

2. Jika nilai signifikansi atau Sig (2-tailed) < 0.05 , maka H0 ditolak dan Ha diterima

Berdasarkan tabel output independent sample T-test di atas diperoleh nilai Sig.(2-tailed) sebesar 0.022 yang berarti lebih kecil dari 0.05 , maka sesuai dasar pengambilan keputusan dapat disimpulkan bahwa $\mathrm{H} 0$ ditolak dan Ha diterima atau terdapat perbedaan antara rata-rata hasil belajar kelas eksperimen dengan kelas control. 


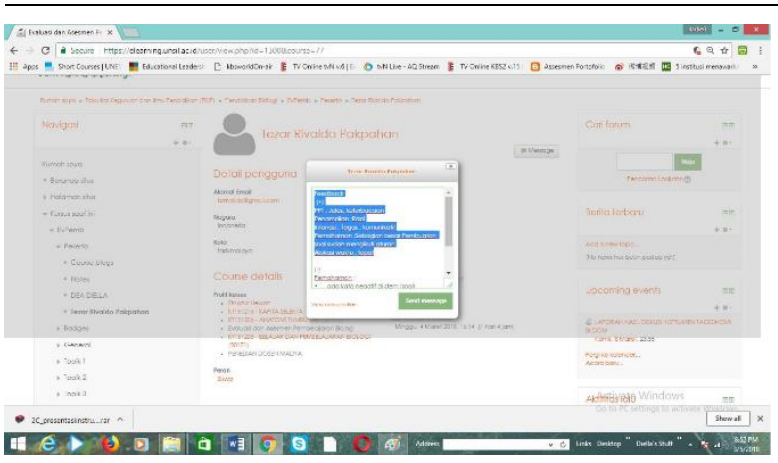

Gambar. 1. Tampilan E-learning saat pemberian feedback secara personal.

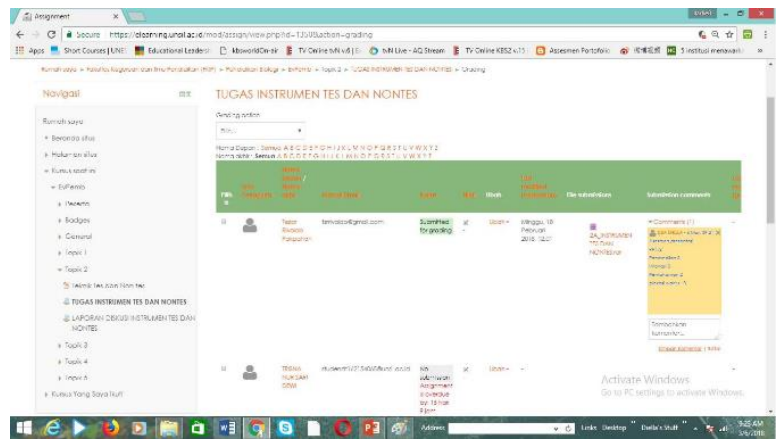

Gambar. 2. Tampilan E-learning saat pemberian feedback kelompok

Berdasarkan uji beda rata-rata hasil belajar, kelas ekperimen yang diberikan assessment for learning berupa pemberian feedback melalui $e$ learning memiliki hasil belajar yang berbeda signifikan dengan kelas kontrol yang hanya mendapatkan pembelajaran melalui e learning (tanpa feedback). Pemberian feedback berdampak pada capaian hasil belajar mahasiswa dan temuan ini relevan dengan penelitian dari (Logan \& Ed, 2015) . Namun jika dilihat dari besarnya rata-rata hasil belajar kelas eksperimen dan kontrol (tabel 2), besarnya nilai (rata-rata) hasil belajar tidak memuaskan, yakni sebesar 54 (kelas eksperimen) dan 45 (kelas kontrol) dari nilai maksimal 100. Pemberian feedback (AfL) tidak memberikan dampak yang besar terhadap hasil belajar (Mcfadzien, 2015). Terdapat beberapa aspek yang menjadi prasyarat dalam menerapkan AfL yakni keterampilan dan pengetahuan pendidik, konten asesmen, kepemimpinan dan kultur dalam memfasilitasi AfL, keterampilan siswa dalam memahami AfL. (Martin \& Ndoye, 2016). Dalam hal ini keterampilan siswa yang kurang memahami AfL merupakan faktor yang menyebabkan pemberian feedback AfL tidak memiliki dampak besar.

Untuk memperkuat temuan ini dilakukan juga perhitungan effect size dari feedback terhadap hasil belajar dengan menggunakan rumus Cohen dan diperoleh hasilnya sebesar 0.60 dan nilai ini bermakna pengaruh yang sedang (berdasarkan kriteria Conhen). besaran effect size dari feedback yang diberikan dalam beberapa cara salah satunya yakni melalui computer-assisted

instructionl feedback sebesar 0.52 ( interpretasi

Tabel 1.

Hasil uji normalitas daa hasil belajar

\begin{tabular}{ccccccc}
\hline \hline Metode & \multicolumn{3}{c}{ Kolmogorov - Smirnov } & & \multicolumn{3}{c}{ Shapiro - Wilk } \\
\hline Metode & Stats & Df & Sig & stats & Df & Sig \\
Eksp & .105 & 30 & $.200^{*}$ & .962 & 30 & .343 \\
Kontrol & .087 & 30 & $.200 *$ & .964 & 30 & .388 \\
\hline \hline
\end{tabular}

Tabel 2.

Group statistic

\begin{tabular}{ccccc}
\hline \hline Metode & $\mathrm{N}$ & Mean & Std Dev & $\begin{array}{c}\text { Std Error } \\
\text { Mean }\end{array}$ \\
\hline Eksperimen & 30 & 54.4667 & 11.16402 & 2.03836 \\
Kontrol & 30 & 45.6050 & 17.36887 & 3.17111 \\
\hline \hline
\end{tabular}

Tabel 3.

Hasil independent sample test

\begin{tabular}{|c|c|c|c|c|c|c|c|c|}
\hline & \multicolumn{2}{|c|}{$\begin{array}{c}\text { Levene's test } \\
\text { for equality } \\
\text { of variance }\end{array}$} & \multicolumn{6}{|c|}{ T-test for equality of means } \\
\hline & $\mathrm{F}$ & Sig & $\mathrm{T}$ & Df & $\begin{array}{l}\text { Sif. } 2 \\
\text { tail }\end{array}$ & $\begin{array}{c}\text { Mean } \\
\text { Diff }\end{array}$ & $\begin{array}{l}\text { Std } \\
\text { Error }\end{array}$ & $\begin{array}{c}95 \% \\
\text { confif } \\
\text { diff }\end{array}$ \\
\hline $\begin{array}{l}\text { Equal variance } \\
\text { assumed }\end{array}$ & 7.25 & .009 & 2.35 & 58 & .022 & 8.86 & 3.76 & $\begin{array}{l}1.3 \\
16\end{array}$ \\
\hline $\begin{array}{c}\text { Equal variance } \\
\text { not assumed }\end{array}$ & & & 2.35 & 49.4 & 0.23 & 8.86 & 3.76 & $\begin{array}{l}1.2 \\
16\end{array}$ \\
\hline
\end{tabular}

berdasarkan tabel Cohen = cukup). Temuan tersebut memiliki kedekatan effect size dalam penelitian ini yaitu feebdback diberikan melalui elearning (Dye Spradlin, Ackerman, \& Dye, 2010).

\section{B. Motivasi Belajar}


Data motivasi belajar dijaring melalui angket motivasi. Uji normalitas (tabel 4) dengan Kolmogorov-Smirnov Test diperoleh Sig sebesar 0.019 untuk kelas eksperimen dan 0.2 untuk kelas kontrol. Nilai Sig kelas eksperimen tersebut lebih kecil dari 0.05 maka data tidak berdistribusi normal. Sedangkan Nilai Sig kelas kontrol lebih besar dari 0.05 maka data berdistribusi normal. Berdasarkan hal tersebut maka uji beda selanjutnya menggunakan pengujian nonparametrik yakni Mann-Whitney U (tabel 6) . Nilai Sig atau P Value sebesar 0,006 $<0,05$. Apabila nilai $\mathrm{p}$ value < batas kritis 0,05 maka terdapat perbedaan motivasi belajar yang bermakna antara dua kelompok atau yang berarti Ha diterima.

Mahasiswa memiliki sikap positif terhadap proses pemberian feedback yang dikirim melalui pesan pribadi melalui e-learning (gambar 1 dan gambar 2). Feedback yang diberikan mencakup komentar kelebihan dan kekurangan performa tugas dan presentasi yang mereka lakukan. Pemberian feedback yang bersifat pribadi ini dapat menimbulkan motivasi belajar yang cukup baik karena mereka merasa kinerjanya mendapat perhatian dan penghargaan (Baranek, 2015). Peserta didik senantiasa memiliki motivasi dalam

Tabel 4.

Test of Normality Motivation

\begin{tabular}{ccccccc}
\hline \hline Metode & \multicolumn{3}{c}{ Kolmogorov - Smirnov } & \multicolumn{3}{c}{ Shapiro - Wilk } \\
\hline Metode & Stats & Df & Sig & stats & Df & Sig \\
Eksp & .175 & .30 & .019 & .879 & 30 & .003 \\
Kontrol & .121 & 30 & $.200^{*}$ & .964 & 30 & .129 \\
\hline \hline
\end{tabular}

Tabel 5.

Rank motivation

\begin{tabular}{cccc}
\hline \hline Metode & $\mathrm{N}$ & Mean & $\begin{array}{c}\text { Sum of } \\
\text { Rank }\end{array}$ \\
\hline Eksperimen & 30 & 36.6 & 1100.50 \\
Kontrol & 30 & 24.32 & 729.50 \\
Total & 60 & & \\
\hline \hline
\end{tabular}

Tabel 6.

Test Statistic

\begin{tabular}{cc}
\hline \hline & Skor motivasi \\
\hline Mean - whitney U & 264.500 \\
Wilcoxon W & 729.500 \\
Z & -2.751 \\
Asymp Sig (2-tailed) & .006 \\
\hline \hline
\end{tabular}

mengerjakan tugas dan proses pemebelajaran seluruhnya. Pemberian feedback dapat membuat peserta didik selalu termotivasi selama proses pembelajaran (Ponte et al., 2009).

\section{Keaktifan}

Keaktifan belajar diindikasikan dengan munculnya pertanyaan dan tanggapan selama proses pembelajaran dan presentasi (Ningsih, Soetjipto, \& Sumarmi, 2017). Presentasi meliputi sepuluh topik asesmen. Pengambilan data keaktifan dilakukan melalui observasi jumlah pertanyaan dan tanggapan selama proses diskusi setelah presentasi. Sebaran jumlah pertanyaan dan tanggapan dapat dilihat pada grafik 1. Jumlah pertanyaan dan tanggapan yang muncul di kelas eksperimen menunjukkan dinamika tergantung pada topik diskusi. Tidak nampak kecenderungan naik atau turun. Namun, jika dibandingkan dengan kelas kontrol, maka jumlah pertanyaan dan tanggapan di kelas eksperimen jumlahnya lebih banyak. Signifikansi perbedaan keaktifan kedua kelas tersebut dapat dibuktikan dengan uji beda (indenpent $\mathrm{T}$ test) yang hasilnya ditunjukkan pada tabel 8. Berdasarkan uji normalitas dengan Kolmogorov-Smirnov Test diperoleh sig sebesar 0.2 untuk kelas eksperimen dan 0.179 untuk kelas kontrol. Kedua nilai Sig tersebut lebih besar dari 0.05 maka kedua data berdistribusi normal.

Hipotesis

HO : tidak terdapat perbedaan keaktifan belajar antara kelas eksperimen dengan kelas kontrol

Ha : terdapat perbedaan keaktifan belajar antara kelas eksperimen dengan kelas kontrol

Dasar pengambilan keputusan

1. Jika nilai signifikansi atau Sig (2-tailed) > 0.05, maka H0 diterima dan Ha ditolak

2. Jika nilai signifikansi atau Sig (2-tailed) < 0.05, maka $\mathrm{HO}$ ditolak dan $\mathrm{Ha}$ diterima Berdasarkan tabel output independent sample Ttest di atas diperoleh nilai Sig.(2-tailed) sebesar 0.001 yang berarti lebih kecil dari 0.05 , maka sesuai dasar pengambilan keputusan dapat disimpulkan bahwa H0 ditolak dan Ha diterima atau terdapat perbedaan keaktifan belajar antara kelas eksperimen dengan kelas kontrol. 
Motivasi belajar yang muncul akibat pemberian feedback berdampak pada munculnya keaktifan mahasiswa untuk bertanya tentang apa yang belum mereka pahami dan memberikan tanggapan berdasarkan apa yang telah mereka pelajari. Feedback terbukti efektif dalam mengatur partisipasi aktif peserta didik selama proses pembelajaran (Ningsih, Soetjipto, \& Sumarmi, 2017). Selama proses diskusi umumnya muncul pertanyaan yang berfokus pada ambiguitas instrumen soal dan tanggapan tentang kesesuaian antara indikator dan soal serta rubrik penilaian. Mahasiswa yang teliti cenderung lebih banyak melontarkan tanggapan dibandingkan pertanyaan (Huang \& Hu, 2015) . Topik diskusi seluruhnya adalah tentang penyusunan instrumen asesmen dan penilaiannya, karena mereka telah terbiasa dengan konten feedback yang diberikan dosen, maka tanggapan yang muncul biasanya masih sejenis dengan komentar (feedback) yang pernah mereka terima (Moore \& Teather, 2013) . Peserta didik menerapkan konten feedback tersebut untuk melakukan peer assessment ketika proses diskusi. Penggunaan AfL dengan kriteria feedback yang jelas penting untuk kesuksesan peer dan self assessment (Logan \& Ed, 2015). Feedback yang diterima setiap mahasiswa dapat

Tabel 7

Test of normality for activity

\begin{tabular}{ccccccc}
\hline \hline \multirow{2}{*}{ Metode } & \multicolumn{3}{c}{ Kolmogorov - Smirnov } & \multicolumn{3}{c}{ Shapiro - Wilk } \\
\hline Metode & Stats & Df & Sig & stats & Df & Sig \\
Eksp & .202 & 10 & $.200^{*}$ & .924 & 10 & .390 \\
Kontrol & .222 & 10 & .179 & .912 & 10 & .296 \\
\hline \hline
\end{tabular}

Tabel 8

Independent samples tet for activity

\begin{tabular}{|c|c|c|c|c|c|c|c|c|}
\hline & \multicolumn{2}{|c|}{$\begin{array}{l}\text { Levene's test } \\
\text { for equality } \\
\text { of variance }\end{array}$} & \multicolumn{6}{|c|}{ T-test for equality of means } \\
\hline & $\mathrm{F}$ & Sig & $T$ & Df & $\begin{array}{c}\text { Sif. } 2 \\
\text { tail }\end{array}$ & $\begin{array}{c}\text { Mean } \\
\text { Diff }\end{array}$ & $\begin{array}{l}\text { Std } \\
\text { Error }\end{array}$ & $\begin{array}{c}95 \% \\
\text { confif } \\
\text { diff }\end{array}$ \\
\hline $\begin{array}{c}\text { Equal variance } \\
\text { assumed }\end{array}$ & 5.17 & .035 & 3.93 & 18 & .001 & 4.60 & 1.16 & $\begin{array}{c}2.1 \\
7.05\end{array}$ \\
\hline $\begin{array}{l}\text { Equal variance } \\
\text { not assumed }\end{array}$ & & & 3.93 & 14.4 & .001 & 4.60 & 1.16 & $\begin{array}{c}2.1 \\
7.10\end{array}$ \\
\hline
\end{tabular}

mereka jadikan informasi untuk memperbaiki pemahaman dan kinerjanya dalam mengerjakan tugas penyusunan instrumen dan menilai atau menanggapi kinerja rekannya dalam tugas yang sama (peer assessment) (Karami \& Rezaei, 2015)

\section{KESIMPULAN}

Implementasi E-learning berbasis assessment for learning (AfL) berupa pemberian feedback berpengaruh positif terhadap hasil belajar, motivasi belajar dan keaktifan kelas mahasiswa. Hasil belajar kelas eksperimen berbeda signifikan dengan kelas kontrol tetapi besarnya nilai hasil belajar tidak memuaskan. Pemberian E-learning berbasis AfL memiliki effect size yang sedang terhadap hasil belajar. Motivasi belajar dan keaktifan kelas eksperimen pun menunjukkan perbedaan yang signifikan dengan kelas kontrol.

\section{UCAPAN TERIMA KASIH}

Penelitian ini dibiayai oleh Ditjen Penguatan Riset dan Pengembangan Kementrian Riset, Teknologi, dan Pendidikan Tinggi Republik Indonesia alam Skema Penelitian Dosen Pemula.

\section{DAFTAR PUSTAKA}

Alruwais, N., Wills, G., \& Wald, M. (2018). Advantages and Challenges of Using eAssessment. International Journal of Information and Education Technology, 8(1), 34-37. https://doi.org/10.18178/ijiet.2018.8.1.100 8

Amua-Sekyi, E. T. (2016). Assessment, Student Learning and Classroom Practice: A Review. Journal of Education and Practice, 7(21), 1-6. Retrieved from http://search.ebscohost.com/login.aspx?dir ect $=$ true $\& \mathrm{db}=$ eric $\& A N=E J 1109385 \&$ site $=$ ehost-live

Azizah, S., Khuzaemah, E., \& Rosdiana, I. (2017). Penggunaan Media Internet eXeLearning Berbasis Masalah pada Materi Perubahan Lingkungan untuk Meningkatkan Hasil Belajar Siswa dalam kehidupan sehari-harinya dan juga psikomotor ( keterampilan ) siswa . Proses 
belajar dapat materi dan bahan belajar yang. Scientiae Educatia: Jurnal

Pendidikan Sains, (2005), 197-213. https://doi.org/DOI: http://dx.doi.org/10.24235/sc.educatia.v6i2 .1957

Boffey, P. M. (1970). Japan (II): University turmoil is reflected in research. Science, 167(3915), 147-152. https://doi.org/10.1126/science.167.3915.1 47

Cox, P., \& Godfrey, J. (1997). The importance of assessment procedures to student learning outcomes in religious education. Australian Journal of Teacher Education, 22(2). Retrieved from http://ro.ecu.edu.au/ajte/vol22/iss2/5/

Creswell, J. W., \& Garrett, A. L. (2014). The methods research and the role of educators, 28, 321-333. Retrieved from https://ed.stanford.edu/sites/default/files/jo _gender_mtl_paper.pdf

Don, H. (2017). Blending Formative and Summative Assessment in a Capstone Subject: "It"s not your tools, it's how you use them'. Journal of University Teaching \& Learning Practice, 14(3). Retrieved from http://ro.uow.edu.au/jutlp/vol14/iss3/2

Dye Spradlin, K., Ackerman, B., \& Dye, K. (2010). The Effectiveness of ComputerAssisted Instruction in Developmental Mathematics Recommended Citation. The Effectiveness of Computer-Assisted Instruction in Developmental Mathematics. Retrieved from

http://digitalcommons.liberty.edu/educ_fac _pubs/195

Garrison, D. R., \& Vaughan, N. D. (2017). Blended learning in Highe Education Framework, Principle and Guidelines. European Journal of Education, 3(5), 2940. https://doi.org/10.5281/zenodo.814302

Ghavifekr, S., \& Rosdy, W. A. W. (2015). Teaching and Learning with Technology: Effectiveness of ICT Integration in Schools Simin. International Journal of Research in Education and Science, 1(2), 175-191. https://doi.org/10.1111/j.1365-

2729.2011.00453.x
HPSC, H. P. S. C. (2009). OECD 2008. (Vol. 2010). Retrieved from http://www.hpsc.ie/hpsc/AboutHPSC/Ann ualReports/File,4080,en.pdf

Huang, X., \& Hu, X. (2015). Teachers' and Students' Perceptions of Classroom Activities Commonly Used in English Speaking Classes. Higher Education Studies, 6(1), 87. https://doi.org/10.5539/hes.v6n1p87

Istambul, M. R. (2016). E-Learning Design Activity to Improve Student's Knowledge and Skills: A Case Study of Database Design Courses. International Journal of Information and Education Technology, 6(6), 423-429. https://doi.org/10.7763/IJIET.2016.V6.726

Karami, A., \& Rezaei, A. (2015). An Overview of Peer-Assessment: The Benefits and Importance. Journal for the Study of English Linguistics, 3(1), 93. https://doi.org/10.5296/jsel.v3i1.7889

Kurniawan, F. A. (2017). Pengaruh Pembelajaran Berbasis Web Terhadap Motivasi dan Hasil Belajar Siswa Kelas X SMA Negeri Paguyangan pada Mata Pelajaran FIsika Pokok Bahasan Suhu dan Kalor. Scientiae Educatia: Jurnal Pendidikan Sains, 6, 1-7. https://doi.org/DOI: http://dx.doi.org/10.24235/sc.educatia.v6i1 .1279

Logan, B., \& Ed, D. (2015). Reviewing the value of self-assessments: Do they matter in the classroom? Research in Higher Education Journal, 29(September), 1-11.

Martin, F., \& Ndoye, A. (2016). Using Learning Analytics to Assess Student Learning in Online Courses. Journal of University Teaching \& Learning Practice, 13(133). https://doi.org/10.1111/j.15405885.2008.00321.x

Mcfadzien, N. (2015). Why is effective feedback so critical in teaching and learning? Journal of Initial Teacher Inquiry, 1.

Moore, C., \& Teather, S. (2013). Engaging students in peer review: Feedback as learning. Issues in Educational Research, 23(2 SPL), 196-211.

Ningsih, Soetjipto, B. E., \& Sumarmi. (2017). 
Improving the Students' Activity and Learning Outcomes on Social Sciences Subject Using Round Table and Rally Coach of Cooperative Learning Model. Journal of Education and Practice, 8(11), 30-37. Retrieved from http://ezproxy.lib.uconn.edu/login?url=http s://search.ebscohost.com/login.aspx?direct $=$ true $\& \mathrm{db}=$ eric $\& A N=E J 1139772 \&$ site $=$ eho st-live

Özad, B. E., \& Kutoğlu, Ü. (2010). The use of the internet in media education. Turkish Online Journal of Educational Technology, 9(2), 245-255. https://doi.org/10.1097/01241398199103000-00014

Ozaki, T. (2008). Research Methods in Education. https://doi.org/10.1111/j.14678527.2007.00388_4.X

Patonah, S., Rahardjo, S. B., Cari, C., \& Sajidan, S. (2017). Learning Model of Attention, Relevance, Confidence, Satisfaction (ARCS) Supported by Video Tutorial to Improve the STudents' Learning Motivation in Vocational High School, 80(Icecsd), 185-189.

Ponte, E., Paek, P., Braun, H., Trapani, C., \& Powers, D. (2009). Using assessment and feedback to enhance teachers' reported use of assessment and feedback. Journal of MultiDisciplinary Evaluation, 6(12).

Sanchez, J. D. (2011). Effect of Learning Activity on Students' Motivation, Physical Activity Levels and Effort Persistence. Journal of Applied Measurement, 12(2), 106-123.

Shabani, K., Khatib, M., \& Ebadi, S. (2010). Vygotsky's Zone of Proximal Development: Instructional Implications and Teachers' Professional Development. English Language Teaching, 3(4), 237248. https://doi.org/10.5539/elt.v3n4p237

Ulva, N. L., Kantun, S., \& Widodo, J. (2018). Penerapan E-Learning Dengan Media Schoology Untuk Meningkatkan Motivasi Dan Hasil Belajar Siswa Pada Kompetensi Dasar Mendeskripsikan Konsep Badan Usaha Dalam Perekonomian Indonesia. JURNAL PENDIDIKAN EKONOMI: Jurnal Ilmiah Ilmu Pendidikan, Ilmu
Ekonomi Dan Ilmu Sosial, 11(2), 96. https://doi.org/10.1016/S00033472(82)80068-7 